\title{
Intestinal Fistula excluding Rectum and Anus
}

National Cancer Institute

\section{Source}

National Cancer Institute. Intestinal Fistula excluding Rectum and Anus. NCI Thesaurus.

Code C34614.

An abnormal connection between the intestine and another epithelial-lined structure, but that does not include the rectum or anus. 